\title{
Mooring system design and verification for a floating vertical axis wind turbine
}

\author{
Fausto Raschioni $\mathrm{i}^{\mathrm{a}, \mathrm{b}, \mathrm{c}^{*}}$, Roberto Longo ${ }^{\mathrm{a}}$, Ali Mehmanparast ${ }^{\mathrm{b}}$, Cesare \\ Mario Rizzo ${ }^{\mathrm{c}}$
}

${ }^{a}$ Longitude Consulting Engineers Limited, Ibex House, 42-47 Minories, London, EC3N 1DY

${ }^{\mathrm{b}}$ Cranfield University, School of Energy, Cranfield, Bedfordshire, MK43 0AL

${ }^{c}$ University of Genoa, DITEN, Via Montallegro 1, Genova, 16145

\begin{abstract}
Keywords:
Floating wind turbine

Vertical axis wind turbine

Floating axis wind turbine

Mooring system

Spar floater
\end{abstract}

ULS analysis

\section{A B S T R A C T}

The aim of this study is to investigate the technical feasibility of an innovative vertical axis floating wind turbine concept with the main focus on the design and verification of the mooring system. The study is developed through iterative processes in order to identify the optimum design for the new floating wind turbine concept. The Ultimate Limit State (ULS) criteria have been considered to verify the integrity of the mooring system in the extreme environmental conditions with a 50-year return period. For this purpose, time domain dynamic analysis has been performed using the commercial software OrcaFlex [1]. Although the analysis is carried out for a specific site deemed suitable for the project, the results can be used as an input for any future application in other locations. The present study is intended to be a proof of concept with a proposed scientific framework for optimisation of the mooring system which is considered to be a crucial part in the design of floating wind turbines due to their complex dynamic behaviour.

*Corresponding author. Tel +393393 882499

E-mail address: fausto.raschioni@gmail.com 


\section{Introduction}

With enormous reductions in the design and operational life costs within the last few years, offshore wind has been recognised as one of the most promising sources of renewable energy to face the world energy demand and carbon emissions reduction targets. Knowing that the number of shallow water sites for bottom-fixed offshore wind turbines will reach its limit in the future, floating wind farms can represent a unique opportunity to unlock the energy production potential in deeper waters and further away from the shore. Today, global interests are focused on floating wind energy and many new concepts of offshore floating wind turbines have been developed, as presented in a report published by Carbon Trust [2].

At the beginning of 2018, about 50 MW of electricity was produced globally from floating offshore turbines, with most of the power generated in Europe, specifically in the UK. Predictions imply that the floating offshore market is expected to grow dramatically in the coming years, reaching more than $12 \mathrm{GW}$ of global electricity production by 2030 [3]. This great potential has led to the creation of new concepts of floating wind turbines which require further feasibility studies prior to commercialisation. The new concepts are aimed at resolving the technological challenges and issues associated with floating wind turbines and, upon completion of proof of concept, promise efficient technologies for the operation of future floating wind turbines around the world.

\subsection{Overview of the floating vertical axis wind turbine concept}

The focus of this study is on the feasibility analysis of a new concept of floating vertical axis wind turbine (FVAWT) design developed by AC Biode start-up in Japan. The novelty of the design lies within the configuration of the wind turbine, which is characterised by a vertical axis turbine supported by a spar support structure which is free to rotate following the rotation of the rotor. The concept appears for the first time in [4] with the proposed name of FAWT (Floating Axis Wind Turbine), to emphasize the fact that the turbine is tilted during operations. Since the FVAWT can allow for a large tilt angle (up to 20deg), there is no need for a large heeling restoring moment and the floater structure can be designed on a small and compact scale, which significantly reduces the fabrication costs. This would not be possible with a Horizontal Axis Wind Turbine (HAWT), which typically has a higher centre of gravity implying higher stability needs. This new floating wind turbine concept has important advantages, compared to a conventional HAWT. Some of these advantages are: HAWTs have a higher centre of gravity, therefore larger structures are needed at the bottom for stability/counteracting; HAWTs need Power Take Off (PTO) at the top which is "delicate", since it can be affected by excessive movements and accelerations due to the large distance from the centre of rotation of the structure; and finally HAWTs have yaw control mechanism to adjust their turbine axis to changing directions whereas VAWT 
can work efficiently without any mechanism since they can catch the wind from every direction. An example of the spar-supported FVAWT concept is shown in Figure 1.

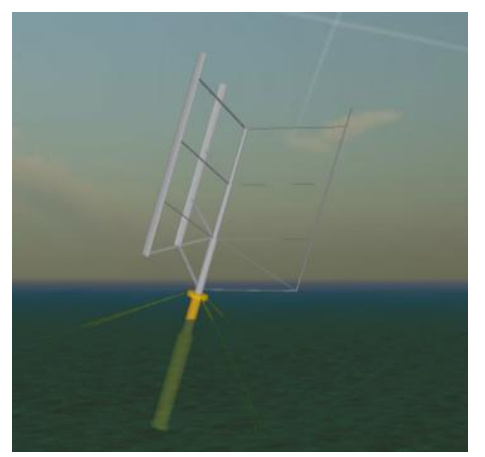

Figure 1. Floating Vertical Axis Wind Turbine (FVAWT) concept

\subsection{Review of the existing floating concepts}

The challenge that the floating wind sector is currently facing is to identify the best design solutions to minimise costs, improve the process of the construction, installation and maintenance, and optimise the electrical and mooring systems, which are the two most critical components in offshore floating wind turbines [3]. The standards formulate the design criteria of the mooring system in terms of Ultimate Limit State (ULS), Accidental Limit State (ALS) and Fatigue Limit State (FLS). The ULS is the first criterion which has to be verified, and it aims to ensure that each line of the mooring system has adequate strength to withstand the load effects imposed by extreme environmental loading conditions [5]. High impulsive forces due to extreme events are considered to have severe effects on the structural integrity of the components. It is evident from previous studies that the stresses induced by extreme events have a significant impact on the fatigue life of floating wind turbines, particularly on the mooring system which experiences many high impulsive loads during its operational life cycles [3]. It has been shown in previous studies that the water depth can play a big role in the cyclic load levels and the mooring system installed in shallow water sites $(<$ $100 \mathrm{~m}$ ) is subjected to completely different load levels compared to deep waters [3].

In addition to the mooring system requirements for FVAWT, a design and optimisation process must be taken into account for the specific requirements of the floating structure, in terms of station keeping and stability. For example, in a study performed by Lin et al. [6], two spar types and two Tension Leg Platform (TLP) floaters in different water depths and with different mooring systems (catenary and taut-leg) are compared, in order to investigate the influence of the type of floating platform and the mooring lines layout on the hydrodynamics forces generated. As shown in [6], significant differences in terms of added mass, damping coefficients and the Response Amplitude Operators (RAOs) have been identified. Also shown in [6] is that the stiffness of the mooring lines significantly influences the surge RAO, highlighting the importance of 
the mooring line system and the platform type on the dynamic response of the entire system [6].

A similar study has been undertaken by Borg and Collu [7] where VAWTs with spar, semi-submersible and TLP support structures have been compared with each other. The results in [7] underline the need for developing specific design criteria for FVAWTs, since additional requirements in surge, sway and yaw became necessary, compared with typical HAWTs [7]. A similar study has also been conducted by Vita [10], who in the first part of the his study focuses on the definition of the hydrodynamics forces induced by the rotating movement of the structure by means of Computational Fluid Dynamics (CFD) analysis; the second part covers the design of a VAWT for three different sizes: $2 \mathrm{MW}, 5 \mathrm{MW}$ and $1 \mathrm{~kW}$ (downscale model for experimental test). In another study by Brommundt et al. [8] an optimisation algorithm has been developed which can be potentially applied to any type of floating wind turbines. It has been stated in [8] that an optimisation process must be carried by considering the following limiting criteria:

1. Ultimate loading condition (i.e. line braking strength reduced by a safety factor) must not be exceeded;

2. Loading at the drag embedded anchors are solely horizontal;

3. Translational and rotational excursions of the floater must follow specified limits (e.g., due to constraints from power cables).

The design criteria presented in this work are in line with industry standards for offshore mooring systems such as DNVGL-OS-E301 and API 2SK [5][9] respectively, and these guidelines have been employed in the present study on FVAWTs.

\section{Model Set-up and Characterisation}

\subsection{General overview}

The 5 MW FVAWT, which is the subject of this study and is composed of a sparplatform floater and a vertical axis rotor (Figure 2), has been modelled using the commercial software OrcaFlex. The spar is characterised by a main body, whose function is to provide buoyancy to the structure, and a separate part which connects the main body to the rotor. The rotor is formed by the tower, which can be considered as the shaft of the turbine and three blades connected by 15 "supporting arms" (i.e. five per blade). The PTO system, placed between the spar and the rotor, is the only fixed component of the system which does not spin, and therefore is where the mooring system is attached. The main dimensions of the FVAWT are reported in Table 1. Regarding the spar height and the main diameter, different values have been investigated during the optimisation phase in order to identify the optimum solution. The rotor has been kept the same as the preliminary design. 
Table 1. FVAWT preliminary main dimensions

\begin{tabular}{ccc}
\hline \multicolumn{3}{c}{ Spar } \\
Overall height & $89-92$ & {$[\mathrm{~m}]$} \\
$\begin{array}{c}\text { Main Diameter } \\
\text { Diameter at water level }\end{array}$ & $10-11$ & {$[\mathrm{~m}]$} \\
Rotor & 7 & {$[\mathrm{~m}]$} \\
\hline Diameter & 123 & {$[\mathrm{~m}]$} \\
Tower height & 116 & {$[\mathrm{~m}]$} \\
Blades length & 123 & {$[\mathrm{~m}]$} \\
Blades chord & 5.9 & {$[\mathrm{~m}]$} \\
\hline
\end{tabular}

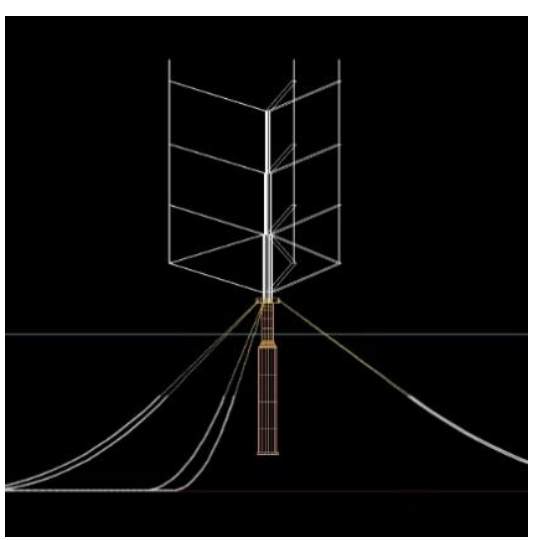

Figure 2. FVAWT concept (view from OrcaFlex model)

\subsection{Environmental criteria}

The Hywind site has been identified as the most suitable in order to conduct this study and meteocean data have been assumed accordingly [11]. This is the only site in the world where a wind turbine with spar-buoy floaters is currently in operation and the similarity between the Hywind and the FVAWT's concept facilitates comparisons, which add value to the present study. Consequently, the environmental data for the selected geographical site have been taken directly from the Hywind Buchan Deep, Metocean Design Basis [12]. Wave and wind data have been taken from the Nora10 hindcast model operated by the Norwegian Meteorological Institute [13], and the hindcast data cover a period of 53 years, from 1958 to 2010.

Table 2. Omni-directional environmental data for $\mathbf{1 , 1 0}$ and 50 years of return period

\begin{tabular}{ccccccc}
\hline \multicolumn{2}{c}{ Environmental Data } & & & \multicolumn{3}{c}{ Return period: } \\
& & & 1 year & 10 year & 50 year \\
\hline Significant Wave Height & $\mathrm{Hs}$ & {$[\mathrm{m}]$} & 7.8 & 9.4 & 10.5 \\
Peak Wave Period & $\mathrm{Tp}$ & {$[\mathrm{s}]$} & 12.4 & 13.5 & 14.3 \\
Wind Speed & & & & & & \\
(1 hour average @ 10m a.m.s.l.) & $\mathrm{U}_{\text {ref }}$ & {$[\mathrm{m} / \mathrm{s}]$} & 26.5 & 29.5 & 31.0 \\
Current Velocity (at sea surface) & $\mathrm{V}_{\text {curr }}$ & {$[\mathrm{cm} / \mathrm{s}]$} & 155.0 & 170.0 & 180.0 \\
\hline
\end{tabular}

Stochastic waves were modelled using a JONSWAP wave spectrum. The ULS analysis was run considering the 50-year return storm, as specified in DNVGL-OS-E301 [5]. The value of the JONSWAP peak-shaped parameter of the spectrum has been calculated based on the formulation presented in Section 3.5.5.5 of the DNVGL-RP-C205 [14]. The current has been assumed to have the surface value of the 10-year return period $\left(\mathrm{V}_{\text {curr }}=170 \mathrm{~cm} / \mathrm{s}\right)$ and a power-law correlation has been adopted to estimate the vertical profile of current velocity along the water depth (power-law exponent is taken as 7.0).

Stochastic wind has been considered and modelled using the NPD/ISO spectrum, as suggested in DNVGL-OS-E301 [5]. The 50-year return wind speed has been assumed as the reference wind speed for the spectrum ( $1 \mathrm{~h}$ average at $10 \mathrm{~m}$ above sea level). The 
wind velocity's vertical profile has been varied by using a power-law function using the following formulation:

$$
U(z)=U(H)\left(\frac{Z}{H}\right)^{\alpha}
$$

where: $U(H)$ is the reference wind speed at $H=10 \mathrm{~m}$; $\mathrm{z}$ is the vertical quote from the mean sea level; and $\alpha=0.12$ is the power-law exponent which depends on the terrain roughness [14].

\subsection{Wave load modelling}

Morison's equation is the formulation generally used for estimating the wave loads acting on a slender offshore structure [16]:

$$
F=C_{D} \rho \frac{A}{2}|v| v+C_{M} \rho V \dot{v}
$$

Where: $\mathrm{A}$ is the drag area, $\mathrm{V}$ is the volume, $C_{D}$ drag coefficient, $C_{M}$ added mass coefficient, $\rho$ water density, $v\left[\frac{m}{s}\right]$ is the fluid velocity relative to the body and $\dot{v}\left[\frac{m}{s^{2}}\right]$ is the consequent acceleration.

Morison's equation can be employed to calculate the wave loads on a cylindrical structure when the diameter of the structure (D) is lower than $0.2 \lambda$ (with $\lambda$ being the wavelength). In such cases, it can be assumed that the waves are not affected by the presence of the structure and therefore it is not necessary to apply diffraction theory for the definition of the hydrodynamic loads. In order to determine the applicability of the Morison's formulation, the wavelength of the significant wave in the 50-year environment has been worked out through the wave dispersion relation. The zerocrossing wave period has been adopted for the solution, as it is considered to be the most common value for wave periods encountered throughout the sea state. Furthermore, the lowest value of water depth for the selected site has been taken into account to consider the worst-case scenario in terms of wavelength in the analysis. Table 3 summarises the main parameters used to verify the applicability of Morison's equation. It can be seen in this table that the maximum applicable diameter is $35.40 \mathrm{~m}$ and the maximum diameter of the spar-buoy floater is designed to be about $10 \mathrm{~m}$. Therefore, Morison's equation is considered to be applicable.

Table 3. Parameters for Morison's formulation applicability criteria

\begin{tabular}{llcl}
\hline Wave peak period & $\mathrm{T}_{\mathrm{p}}$ & 14.30 & {$[\mathrm{~s}]$} \\
Wave zero-crossing period & $\mathrm{T}_{\mathrm{z}}$ & 10.66 & {$[\mathrm{~s}]$} \\
Water depth & $\mathrm{d}$ & 95.00 & {$[\mathrm{~m}]$} \\
Wave number & $\mathrm{K}$ & 0.036 & {$[1 / \mathrm{m}]$} \\
Wavelength & $\lambda$ & 177.00 & {$[\mathrm{~m}]$} \\
Max applicable diameter & $\mathrm{D}_{\lim }$ & 35.40 & {$[\mathrm{~m}]$} \\
\hline
\end{tabular}


Since the analysis was carried out using stochastic waves, it is possible that some of the components with lower periods included in the wave spectrum will be outside the Morison's equation applicability criteria. Furthermore, OrcaFlex presents a so-called "short-wave issue" function [15] in calculating the effects of the waves on a spar buoy. For these reasons it was decided to verify the extent to which the energy of the wave spectrum is associated with the wave components outside the applicability of Morison's equation and to identify those components that might be affected by the "short-wave issue". Three different areas were therefore identified (see Figure 3). Green ticks in Table 4 indicate that the short-wave issue does not affect the system or the applicability of Morison's formulation. As the period decreases (i.e. as the frequencies increase) Morison's equation becomes no longer applicable and the short-wave issue starts to affect the calculations. However, since $99.65 \%$ of the energy spectral density belongs to Zone III, Morison's equation has been considered to be valid through the whole frequency range and the short-wave issue has been neglected.

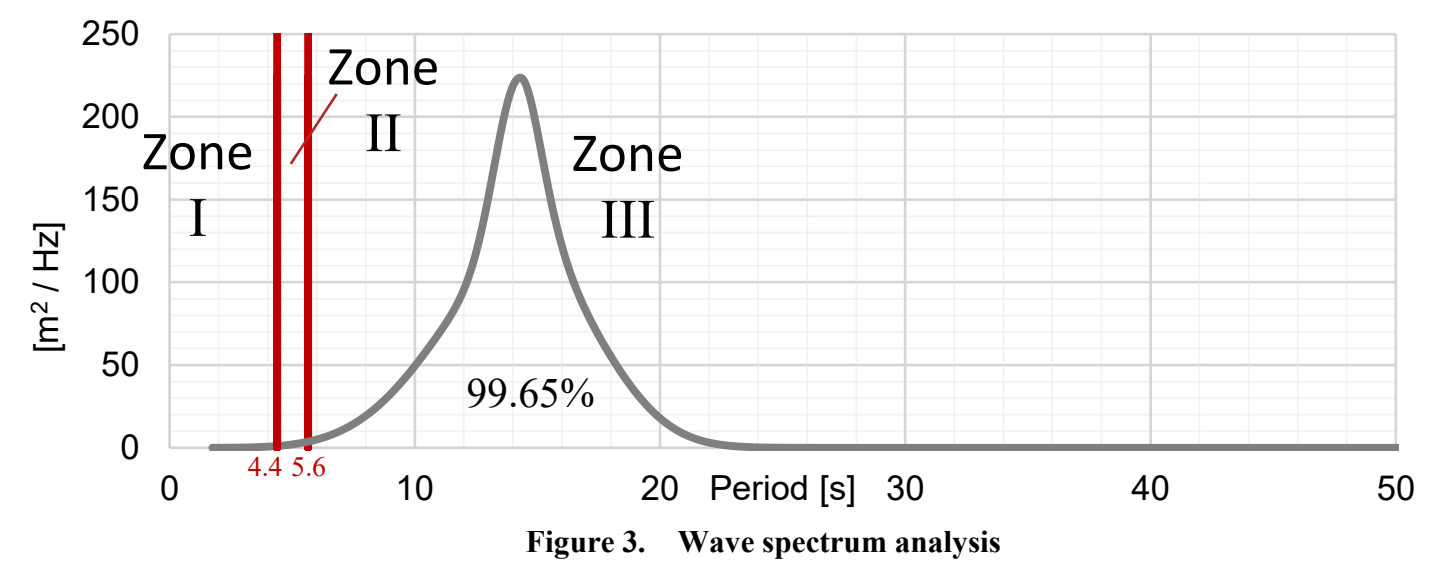

Table 4. Morison and Short-wave issue applicability

\begin{tabular}{llcc}
\hline & Morison & Shortwave issue \\
\hline Zone I $($ Period $\leq 4.4 \mathrm{~s})$ & $x$ & $x$ \\
Zone II $\quad(4.4 \mathrm{~s}<$ Period $\leq 5.6 \mathrm{~s})$ & $\checkmark$ & $x$ \\
Zone III $($ Period $>5.6 \mathrm{~s})$ & $\checkmark$ & $\checkmark$ \\
\hline
\end{tabular}

\subsection{Hydrodynamic characteristics}

The hydrodynamic coefficients, such as the drag and the added mass coefficients, depend on the fluid-structure interaction and are necessary to confer real properties in the model. The estimation of such parameters can be made using the definition of the fluid kinematic properties through the estimation of the following parameters:

- Reynolds number (Re)

- Keulegan-Carpenter number (KC) 
The employment of a wave theory is equally important to allow the calculation of the water particle velocities and estimate the values of the parameters given above. Following DNVGL-RP-C205 guidelines [14], the second-order Stokes wave theory has been taken as the most suitable theory for the environmental conditions of the selected site and, consequently, the wave-particles' velocity has been estimated.

In particular, since the size of the spar body has been kept fixed for this calculation, the water particle velocity has been considered to be the unique parameter with an active role in the estimation of $\mathrm{Re}$ and $\mathrm{KC}$. Therefore, the wave characteristics such as wave height, wave period and water depth, which identify the values of the water particle velocity, have been analysed in order to estimate the parameters. From the analysis, and using the wave loading regimes described in [16], the values of $C_{M}=2$ and $C_{D}=0.62$ have been calculated and set in the spar hydrodynamics characteristics. Using these coefficients, a conservative approach has been taken to proceed with the study, by considering the worst-case scenario for all the floater structure in terms of drag and added mass coefficients. Another hydrodynamic force, which has not been discussed yet, is the damping force which is implemented in OrcaFlex through the unit damping force for normal and axial directions. For simplicity, damping has been initially set to zero in order to obtain conservative results from the simulation.

\subsection{Aerodynamic modelling}

Regarding the tower structure, this is an assembly of three simple cylinders built one on the top of the other. The air acts on the structure along the normal direction creating forces which cannot be neglected, so, similarly to the approach adopted for the spar floater, the drag coefficient $\left(\mathrm{C}_{\mathrm{D}}\right)$ has been estimated in accordance with the literature data. The drag coefficient varies with the Reynolds number; however, $\mathrm{C}_{\mathrm{D}}$ has been assumed to be a constant value of 1.2 along the entire tower length. This assumption ensures that conservative results are obtained in accordance with DNVGL-RP-C205 [14].

The supporting arms have been set as simple 2D flat plates and modelled as wing elements, with lift and drag coefficient calculated in accordance with [17]. The blades have been modelled in OrcaFlex as a single blade turbine and each one has been defined with the aerodynamic characteristics of a specific airfoil along the whole length of the blade. The turbine object in OrcaFlex is not appropriately designed for a VAWT; therefore, specific adjustments have been made from the default options in order to allow the model to simulate the desired geometry. The aerodynamic properties of the airfoil NACA 0012 have been assumed at this stage of the project, as suggested by AC Biode. 


\subsection{Scenarios considered in simulations}

The magnitude and direction of the waves, wind and current are characterised by high irregularity, which determines various load scenarios acting on the turbine. This is why many configurations in terms of environment, direction and system layout have been considered. Figure 4 shows a schematic of a plan view of the turbine.

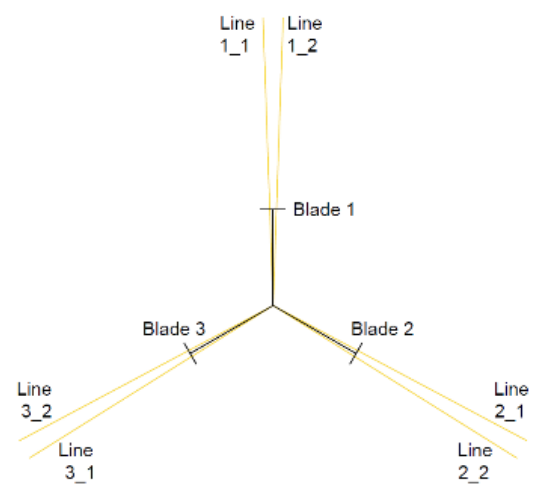

Figure 4. Line and Blade labels

For high wind speeds, the turbine is stopped using a brake and set in a parked condition. In this situation, the final position of the blades is completely random, which means that different drag loads can act on the structure in relation to the disposition of the blades and the direction of the wind. Therefore, 18 scenarios have been analysed, in order to take into account the inherent variability in this process. All 18 cases are represented in Table 5. The configurations analysed are in fact nine, and for each configuration two cases, one with a Collinear and one a Non-Collinear environment, have been considered. Figure 5 shows case scenario numbers 1 and 4, which are characterised by the same configuration but different environments (Collinear and Non-Collinear). The Collinear environment is characterised by the same direction of wave, wind and current, whereas the Non-Collinear environment is characterised by wind and current moved by 30 and 45 degrees respectively from the wave direction.
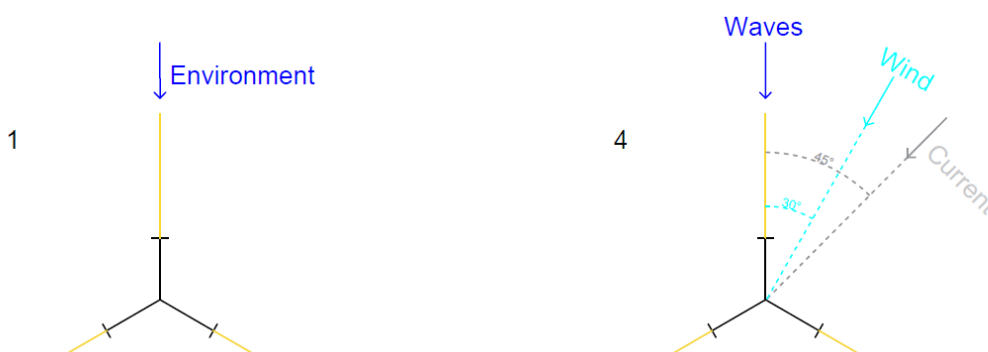

Figure 5. Collinear and Non-Collinear environment (cases 1 and 4) 
Table 5. Case scenarios for OrcaFlex Simulation

\begin{tabular}{cccc}
\hline Case & $\begin{array}{c}\text { Blades position } \\
{[\mathrm{deg}]}\end{array}$ & $\begin{array}{c}\text { Environment } \\
\text { Direction } \\
{[\mathbf{d e g}]}\end{array}$ & $\begin{array}{c}\text { Environment } \\
\text { alignment }\end{array}$ \\
\hline 1 & 0 & 0 & Collinear \\
2 & 0 & 30 & Collinear \\
3 & 0 & 60 & Collinear \\
4 & 0 & 0 & Non-Collinear \\
5 & 0 & 30 & Non-Collinear \\
6 & 0 & 60 & Collinear \\
7 & 30 & 0 & Collinear \\
8 & 30 & 30 & Collinear \\
9 & 30 & 60 & Non-Collinear \\
10 & 30 & 0 & Non-Collinear \\
11 & 30 & 30 & Non-Collinear \\
12 & 30 & 60 & Collinear \\
13 & 60 & 0 & Collinear \\
14 & 60 & 30 & Collinear \\
15 & 60 & 60 & Non-Collinear \\
16 & 60 & 0 & Non-Collinear \\
17 & 60 & 30 & Non-Collinear \\
18 & 60 & 60 &
\end{tabular}

\section{Design and Optimisation: Results and Discussions}

\subsection{Methodology}

The focus of the present study is to optimise the mooring system design for the FVAWT on the selected site with respect to ULS. Since there are many parameters that can considerably influence the response of the system, an iterative process has been employed in this study using OrcaFlex software. The iterative process started with some provisional values assigned to each parameter in initial simulation cycles which were varied at the later stage of the iteration process in order to meet the desired targets. The proposed iteration framework for design optimisation is illustrated in Figure 6. Different case scenarios were analysed using a preliminary design of the mooring system and were subsequently processed in OrcaFlex through the 3 hours (typical stationarity period for sea states) dynamic simulation in the ULS environmental scenario.

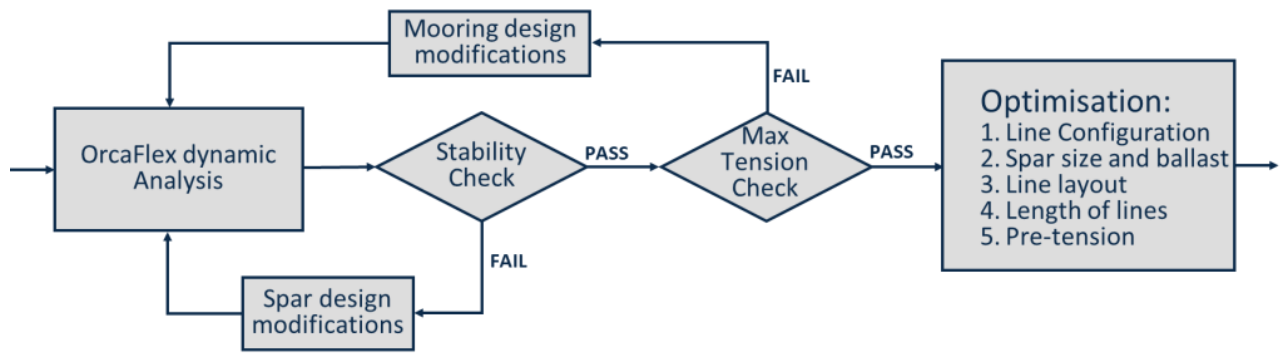

Figure 6. Iteration framework for design optimisation

The first part of the process accounted for the analysis of the tensile loads in the mooring lines and the stability of the structure, which are the fundamental requirements for the design process. The second part focuses on the optimisation of the mooring system and the spar floater. In accordance with the majority of the standards, two main aspects have been analysed for the design of the mooring system: 
- Maximum allowable tension: this aims to ensure the reliability of the system in terms of structural integrity and avoid potential failures in extreme scenarios.

- Maximum excursion: this represents the constraints imposed by some components of the system such as the umbilical and cables in terms of maximum horizontal movement of the system from the static state.

At each stage of the process, the worst-case scenario, in terms of either stability or mooring tensions, has been considered. As a matter of fact, when some parameters are changed, the entire dynamics of the system could potentially be affected, and one of the considered cases which was not initially critical could become the worst case. It is important to mention that the design and optimisation of the mooring system strongly depends on the chosen geographical site. Therefore, in addition to a potential mooring system design solution for the selected site and proving the feasibility of the concept, this study aims to illustrate the suitability of the proposed framework for design optimisation in other locations.

\subsection{Stability analysis}

In accordance with the diagram presented in Figure 6, the first iteration regarded the stability check and, specifically, aimed to ensure that there was always enough clearance between the rotor and the sea surface, in order to avoid potential problems caused by the waves hitting the structure. Several cases have been investigated and compared. The draft has been kept fixed and equal to the design value, so the amount and type of ballast and the diameter of the spar have been considered as the parameters in the analysis. The correction for free surfaces has been considered for cases characterised by the presence of water ballast.

Submerged length of Blade 2

[m]

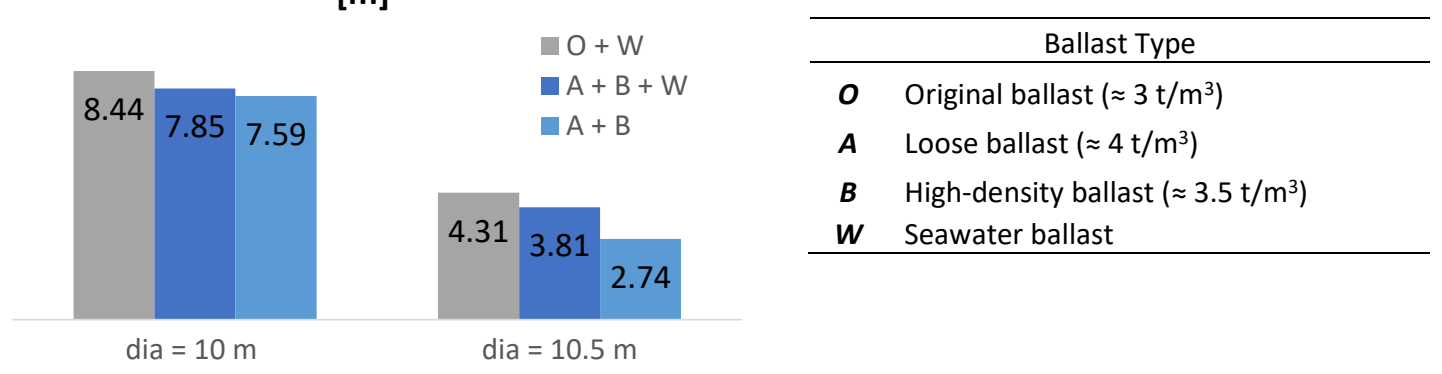

Figure 7. Ballast configuration effects on FVAWT's stability (Submerged length of Blade 2)

It can be seen in Figure 7 that increasing the stability of the structure, the submerged length of the blade decreases as predictable. However, since the influence of the ballast and the diameter have been found to be insignificant to avoid the submergence of blades, the overall height of the spar buoy has been increased to move up the rotor (Figure 8). By using this strategy, the model can ensure that more than two metres of 
clearance from the bottom of the turbines and the sea surface can be achieved; however, this implies the reduction of the general stability of the structure due to the heigth change in the centre of gravity.
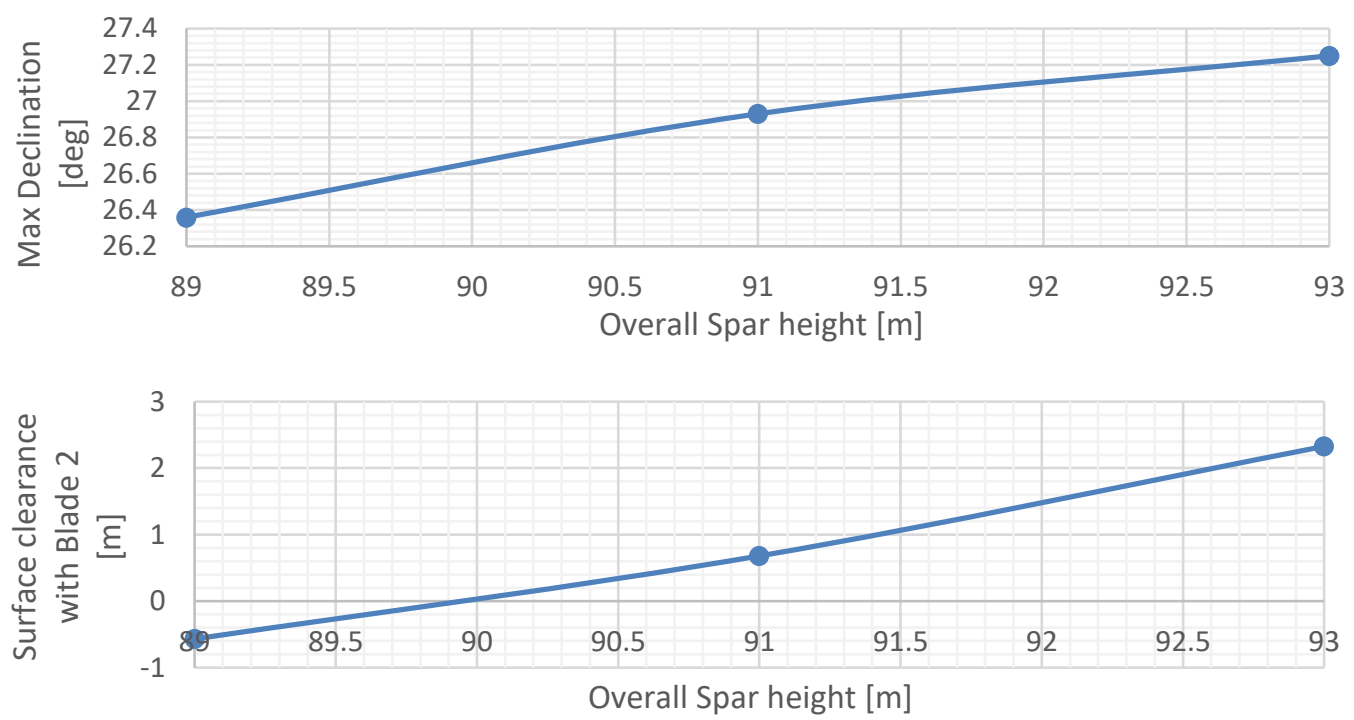

Figure 8. Spar height modification effects on FVAWT's stability

The influence of the spar diameter on the stability is analysed and the results are shown in Figure 9. It can be seen in this figure that the maximum declination decreases linearly by increasing the main diameter of the spar structure. Also seen in Figure 9 is that a difference of $1 \mathrm{~m}$ in the spar diameter is translated into approximately 6 degrees of declination reduction, which shows the significant effect of the spar diameter on the structure's stability.

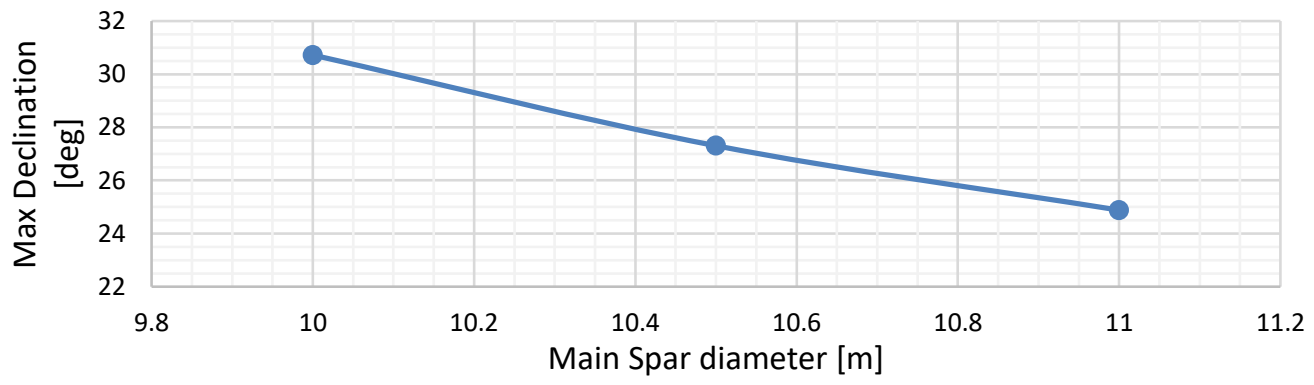

Figure 9. Maximum Declination vs. Main spar diameter

\subsection{Maximum Tension}

The second step in the analysis is to check the maximum tension in the mooring lines to ensure that they are less than the critical value. Three cases have been implemented in OrcaFlex, where the size of the lines has been increased gradually until the design requirements were achieved. The spar inertia properties have been modified by scaling up the amount of ballast for each case. By increasing the size of the mooring lines, the weight of the mooring system which acts on the floater increases accordingly, and therefore the spar's total weight needs to be adjusted. The results in Table 6 show that 
the maximum tension stays below the limit (60\% of the Minimum Breaking Load [9]) for both chain and rope in case number 3 .

Table 6. Max tension measured for different size of mooring lines

\begin{tabular}{cccccc}
\hline Case & Type & $\begin{array}{c}\text { Diameter } \\
{[\mathbf{m m}]}\end{array}$ & $\begin{array}{c}\text { Limit } \\
{[\mathbf{k N}]}\end{array}$ & $\begin{array}{c}\text { Max Measured } \\
\text { Tension } \\
{[\mathbf{k N}]}\end{array}$ & $\begin{array}{c}\text { Utilisation factor } \\
\text { (Max tension/min(Limit)) }\end{array}$ \\
\hline \multirow{2}{*}{1} & SYNTHETIC & 125 & 6130 & 6888 & \multirow{2}{*}{1.16} \\
\hline \multirow{2}{*}{2} & CHAIN & 100 & 5918 & 6848 & \multirow{2}{*}{1.03} \\
\hline \multirow{2}{*}{3} & SYNTHETIC & 133 & 7006 & 6875 & \multirow{2}{*}{0.92} \\
& CHAIN & 107 & 6671 & 6875 \\
\hline
\end{tabular}

\subsection{Mooring line configuration}

The type of mooring line implemented in the model has been defined using the Hywind's mooring system as a realistic example. Therefore, mooring chains and synthetic ropes have been used in this study. Moreover, an additional case with chains only has also been simulated to perform a comprehensive analysis on the preferred solutions. The amount of synthetic rope and chain is the main factor considered in the analysis of the mooring line configuration. Due to the consequent difference in weight, the spar optimisation has been investigated by adopting two considerations:

a) Adjust the spar ballast (adding mass)

b) Reduce the spar size (losing buoyancy)

The longer the synthetic rope, i.e. less chain in used, the lower the buoyancy needed to ensure the design draft and consequently, the size of the spar buoy can be reduced. Table 7 shows the cases analysed in this study.

Table 7. Cases for line configuration optimisation analysis

\begin{tabular}{ccccc}
\hline \multirow{2}{*}{ Case Number } & \multicolumn{3}{c}{$\begin{array}{c}\text { Ballast Weight increase } \\
{[\mathbf{t}]}\end{array}$} & $\begin{array}{c}\text { Overall spar } \\
\text { Height } \\
\text { [m] }\end{array}$ \\
\cline { 2 - 5 } & Type $\boldsymbol{A}$ & Type $\boldsymbol{B}$ & Water & base \\
\cline { 2 - 4 } 2 & base & base & $/$ & base \\
$3 a$ & base & +34 & +51.9 & -0.6 \\
$3 b$ & base & +36 & $/$ & base \\
$4 a$ & base & +34 & +143 & -1.7 \\
$4 b$ & base & +36 & $/$ & \\
\hline
\end{tabular}

The results show that a minimum adjustment in ballast type $\mathrm{B}$ has been made, even for cases $3 \mathrm{~b}$ and $4 \mathrm{~b}$, which are meant to have modifications only in spar size. This was due to the fact that little changes in the ballast have been made in order to avoid inaccurate measures of the spar height and keep the design draft fixed. In other words, the parameter which has been kept fixed was the distance from the water level to the PTO system, which was assumed to be $20 \mathrm{~m}$. It is clear that, if a "block" of the spar is removed in order to reduce the buoyancy, the draft will change accordingly. In cases $3 \mathrm{a}$ 
and $4 \mathrm{a}$, where ballast water was added to bring back the spar in the design draft, the correction for free surfaces has been considered.
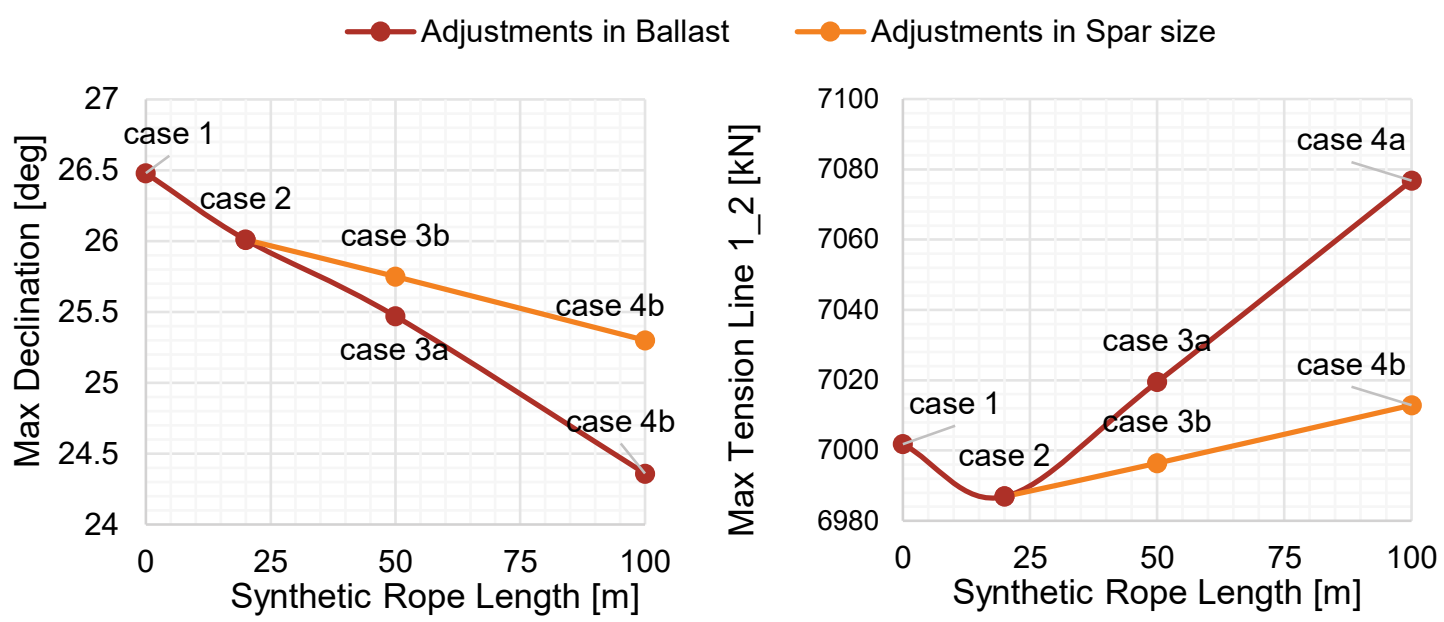

Figure 10. Synthetic rope length vs. Max tension in line 1_2 and Max declination

Thanks to the configuration with $100 \mathrm{~m}$ of synthetic rope and consequently the lower weight, the spar size has been reduced by removing $1.7 \mathrm{~m}$ from the main body of the structure. It means that about 25 tonnes of steel have been saved, as shown in Figure 11. It is interesting to note that the number of tonnes saved follows almost a linear behaviour when the data are plotted against the length of synthetic lines. However, even though material saving which is proportional to the synthetic rope length is beneficial, $100 \mathrm{~m}$ has been set as the higher limit for synthetic lines, beyond which the synthetic part will be too close to the seabed and the risk of abrasion would increase. Furthermore, it can be seen in Figure 10 that the adjustments in the spar size change the lower value of the maximum tension in the mooring lines, but also increase the maximum declination.

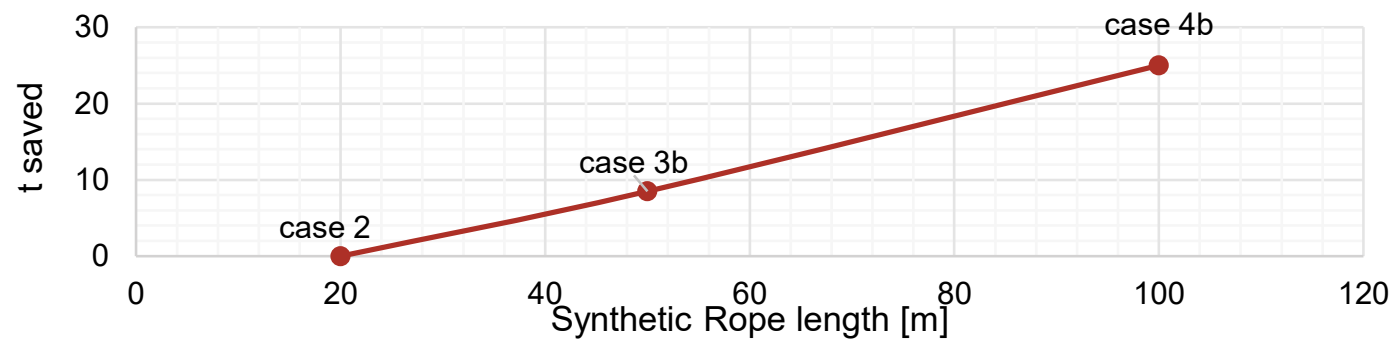

Figure 11. Synthetic rope length vs. tonnes saved from the spar structure

\subsection{Mooring system layout}

Regarding the mooring system layout, three different cases have been analysed. In the base cases, an arch with a 4-degree angle has been considered between the lines. Two additional cases with 8 and 16 degree angles have also been considered and compared to the first case, as shown in Figure 12. The angle between each pair of mooring lines has always been kept fixed at 120 degrees. A greater angle between the lines implies higher stability. Figure 13 shows how the minimum surface clearance with Turbine 2 increases 
by about 2 metres from case 1 to case 3 . However, the maximum tension in the lines experiences a dramatic increase when the angle layout changes from 4 to 16 degrees. It can be seen that in case 2 , the tension is about $8 \%$ higher than the base case. It is interesting to note that the maximum tension curve follows an almost linear trend when the results are plotted against the mooring layout angle.
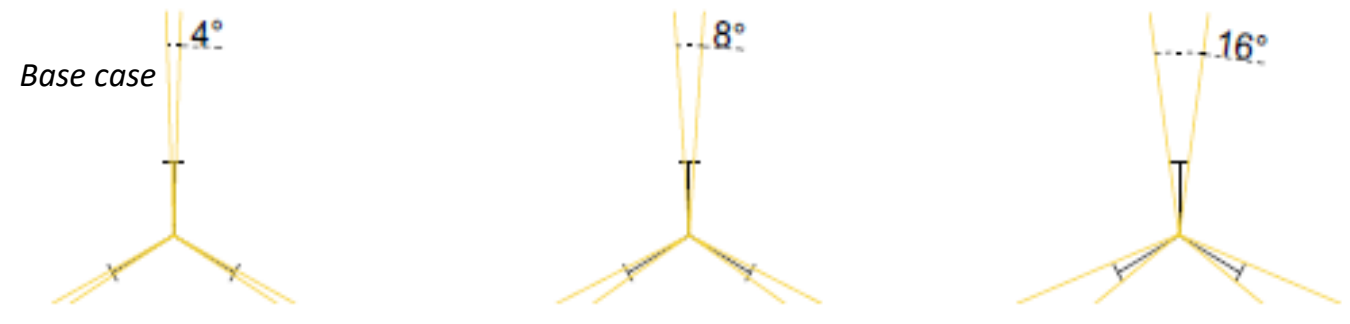

Figure 12. Mooring lines' layout configurations
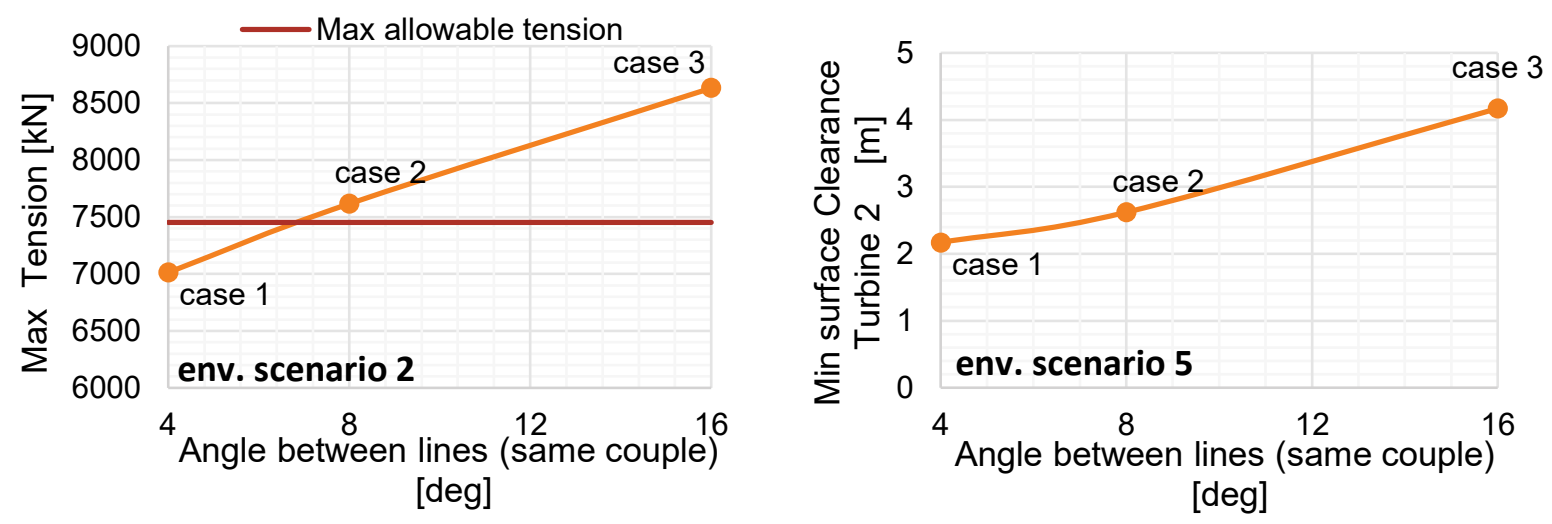

Figure 13. Angle between lines (mooring layout) vs. Maximum tension and Minimum surface clearance

\subsection{Length of the mooring lines}

For the length of the mooring lines, a conservative value was initially considered in the base cases. Obviously, the mooring line length needs to be optimised in order to save material and cost. The length has been adjusted as multiples of the unit lengths in the market (i.e. shot) and then minimised. The shot is the fundamental unit for selling lengths of chain and is equal to $27.432 \mathrm{~m}$. Avoiding the uplift is the only requirement which has been considered for this analysis since the drag anchors need to work without vertical loads. The length of the synthetic rope has been kept fixed to $100 \mathrm{~m}$ and the length of the chains has been adjusted based on the value of the touchdown point measured in the simulations. In this case, no particular outcomes in terms of dynamics 
of the system have been observed, as only the part of the chain located on the ground has been modified.

\subsection{Pre-tension analysis}

The pre-tension is a fundamental design parameter with direct consequences on the stability and dynamic behaviour of the entire system. Therefore, a dedicated pre-tension analysis has been carried out as the final stage of the optimisation phase. With slack mooring lines, the spar structure is allowed to make large motions and with extremely tensioned lines the structure is most likely to stay close to the original position. In order to use the mooring line pre-tension as a variable, the anchor point has been modified in each of the cases analysed by keeping the mooring lines' length fixed. The pre-tension range analysed ranges between 500 and $1000 \mathrm{kN}$, which can be considered as a feasible tension range for floating wind turbines, given that the pre-tension of the Hywind's mooring lines is about $900 \mathrm{kN}$ [18]. The output of the analysis, shown in Figure 14, confirms that the pre-tension has a significant influence on the maximum excursion of the system. The horizontal excursion results in the Y-direction have been found to be the most critical, with the largest value obtained at just over $50 \%$ water depth and a minimum value obtained at approximately $30 \%$ water depth. It is evident from Figure 14 that a difference of $500 \mathrm{kN}$ in the mooring line pre-tension results in just over a $20 \%$ and $10 \%$ change in the $\mathrm{Y}$-direction and $\mathrm{X}$-direction excursion results, respectively.

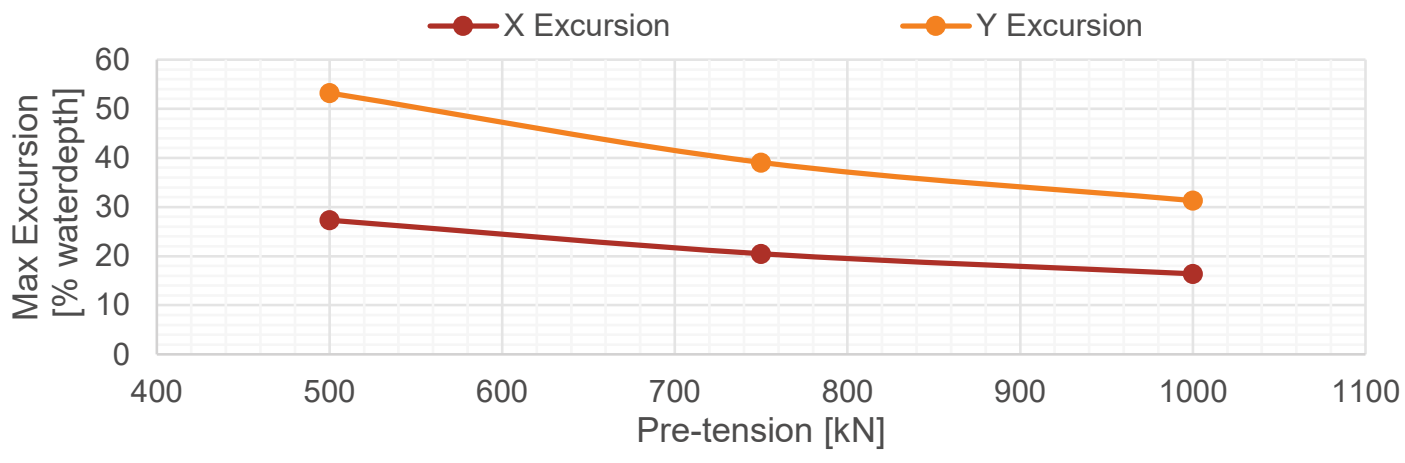

Figure 14. Pre-tension vs. Maximum Excursion at PTO

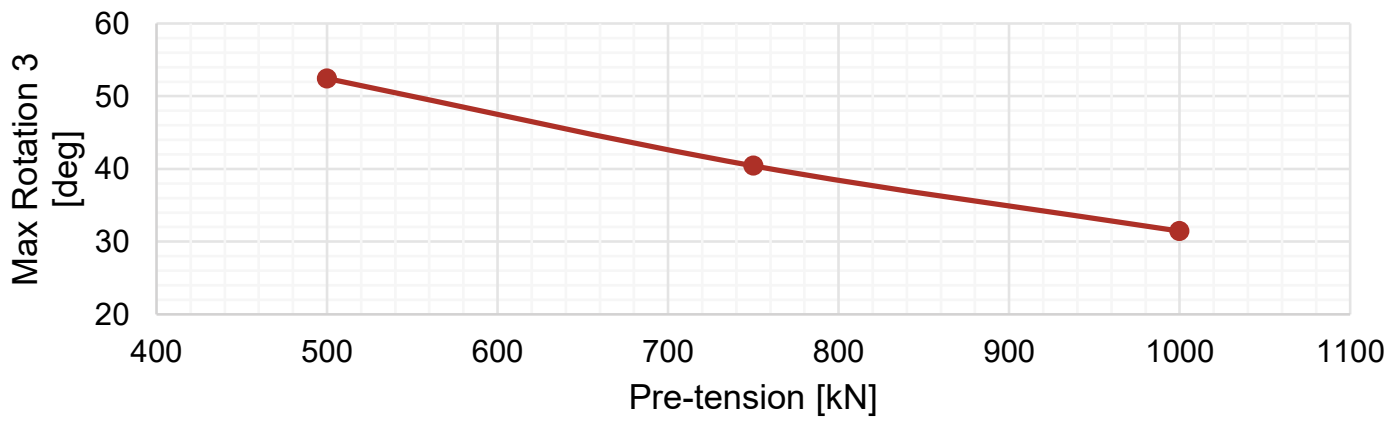

Figure 15. Pre-tension vs. Maximum rotation 3 ( $\mathrm{Z}$ direction)

In addition to the horizontal excursion, the rotation of the rotor around its axis is another important output for specific design constraints. The results in Figure 15 have shown 
that a significant reduction of more than 20 degrees in maximum rotation has been obtained when the pre-tension was increased from 500 to $1000 \mathrm{kN}$. The influence of the pre-tension in terms of declination of the turbine has also been investigated and the results are shown in Figure 16. It can be seen in this figure that the turbine experiences an improvement, by approximately 3 degrees reduction in maximum declination, when the pre-tension was increased from 500 to $1000 \mathrm{kN}$. Interestingly it can also be observed in Figure 16 that the mean value of declination remains unchanged by increasing the pre-tension value.

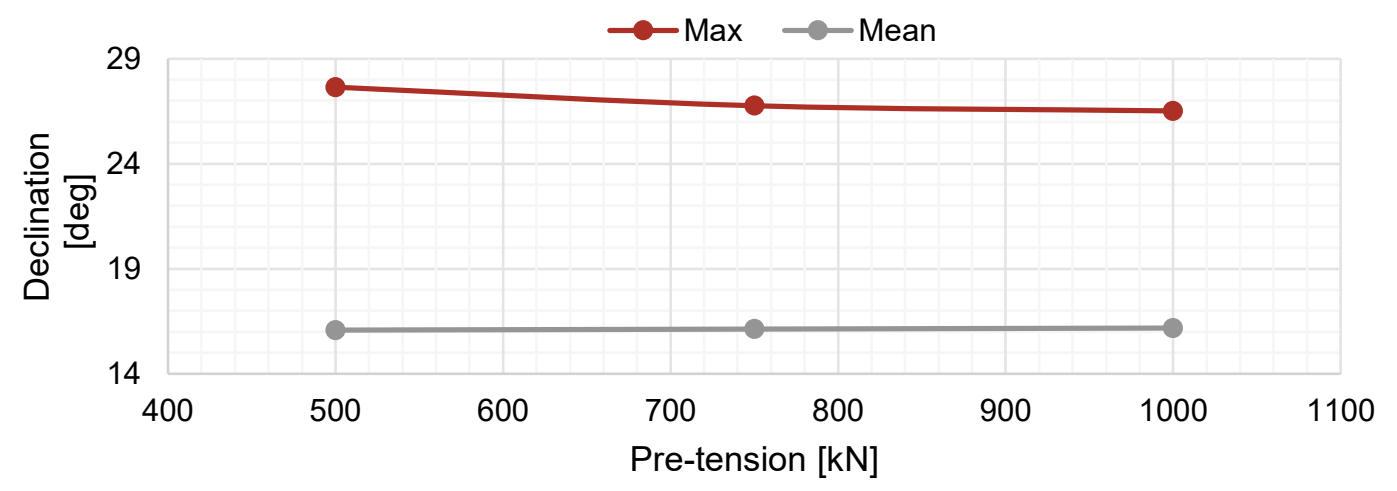

Figure 16. Pre-tension vs. declination of FVAWT

The maximum mooring line tension has been found to be always below the maximum allowable tension. It is interesting to note that the highest value of tension is measured in two different lines between cases with $500 \mathrm{kN}$ and $1000 \mathrm{kN}$ of pre-tension (see Figure 17). $1000 \mathrm{kN}$ causes anchor uplift because the position of the touchdown point overtakes the line length (touchdown point limit). The model with $750 \mathrm{kN}$ of pretension load has been found to give the best solution and therefore has been taken as the optimised model since it implies no issues associated with the mooring line tension and ensures the avoidance of anchor uplift with a minor excursion.
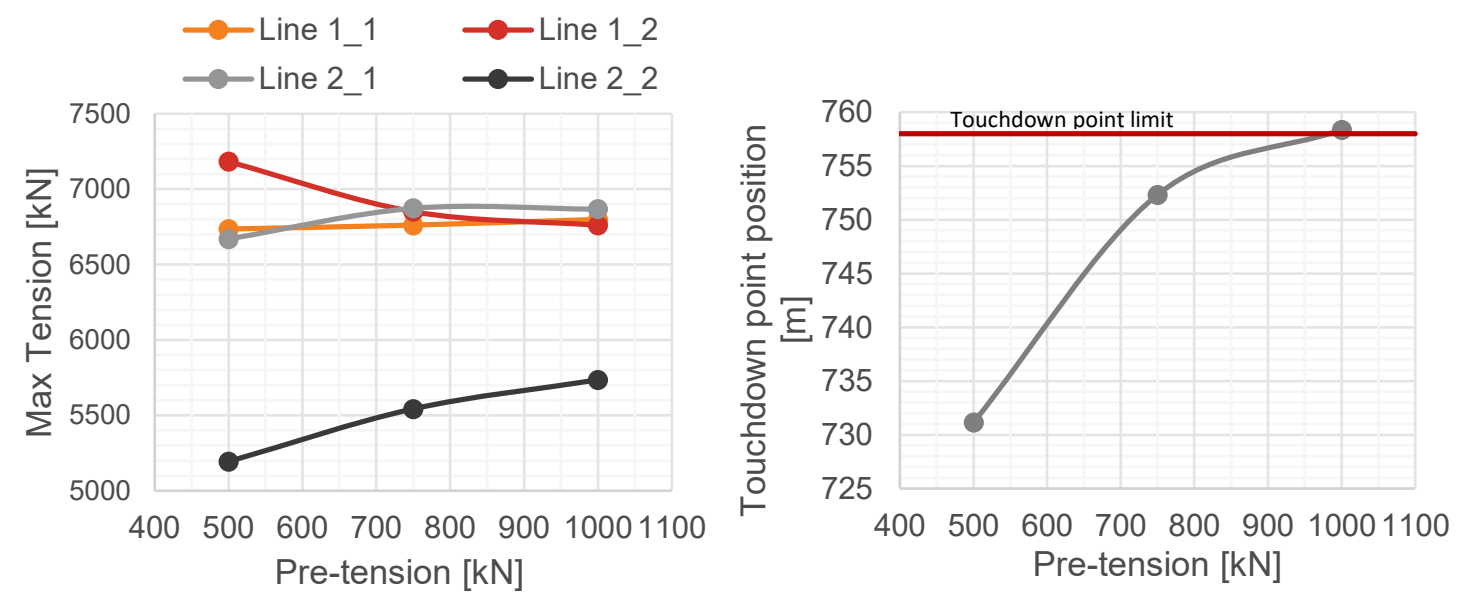

Figure 17. Pre-tension vs. Maximum tension and Touchdown point position 


\subsection{Optimised model}

In this section, the output data of the ULS analysis for the optimised model are presented. The FVAWT structure and the mooring system have been changed significantly, compared with the preliminary cases, in order to satisfy all the requirements. The main features of the optimised model are presented in Table 8 and Table 9.

Table 8. Optimised SPAR properties

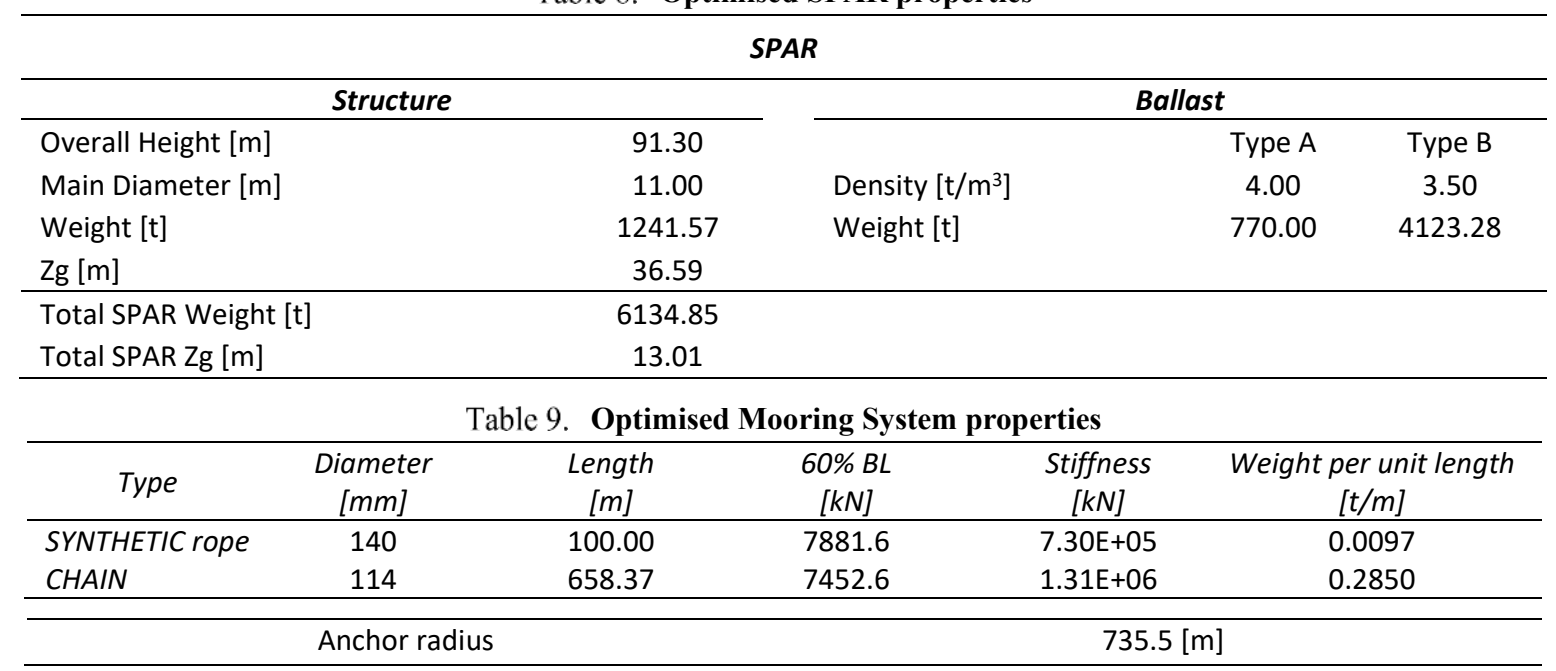

Finally, the mooring system has been completed by adding the anchor, which has not been considered in full detail in the current analysis framework. The choice of the anchor has been made in accordance with the ABS technical report [19], which provides guidelines for the design of the anchoring systems. The Ultimate Holding Capacity (UHC), assumed as the maximum tension measured in proximity to the anchor point, has been estimated as the maximum tension value obtained from the simulations. In the case scenario number 12, this value has been found to be $6762 \mathrm{kN}$. Consequently, the weight of the drag anchor has been estimated to be approximately $40 \mathrm{Mt}$, assuming a medium clay seabed.

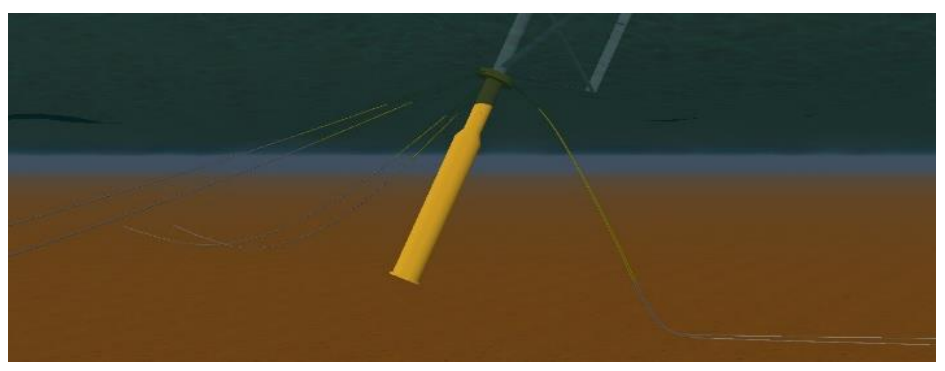

Figure 18. Final optimised model - mooring system view

At this stage, all the design requirements imposed by both the stability issues and the ULS requirements have been successfully fulfilled through the iterative process. The optimised model is characterised by a maximum value of the mooring line tension of $6873 \mathrm{kN}$, which has been found in Line 2_1, measured in proximity to the connection 
with the PTO. It ensures about $580 \mathrm{kN}$ difference compared to the maximum allowable tension and corresponds to about $55 \%$ of the minimum breaking load declared by the manufacturer, which means that an extra $5 \%$ is allowed with respect to the safety factor considered for the ULS limit ( $60 \%$ of the MBL). The data presented in Table 10 are the summary of the maximum and mean excursion of the FVAWT measured at the PTO.

Table 10. Excursion for optimised model

\begin{tabular}{ccc}
\hline & Max & Mean \\
\hline X excursion [\% water depth] & 20.5 & 2.3 \\
Y excursion [\% water depth] & 39.1 & 20.8 \\
Z excursion [\% water depth] & 9.1 & 1.4 \\
Rotation 3 [deg] & 40.4 & 5.7 \\
\hline
\end{tabular}

Figure 19 shows the maximum value of tension measured in each case scenario as a function of the environment direction for each blade configuration in the collinear and non-collinear environment. It can be seen in this figure that the orientation of the mooring lines plays a significant role in the line tension values. This means that the position of the mooring system must be designed by taking into account the most probable environment direction for the selected site. Hence, the best mooring layout configuration is found to be the one with the environment at zero degrees, because it implies the highest value of tension in both the collinear and non-collinear cases. If other angles of the environment were considered, the maximum tension would be characterised by higher values of tension and by significant variations between the collinear and non-collinear cases, which could potentially affect the fatigue life of the mooring lines. Also seen in these results is that the orientation of the blades in relation to the wind direction has a considerable influence on the system and it could be the subject of further aerodynamic analysis in future work to optimise the rotor design.

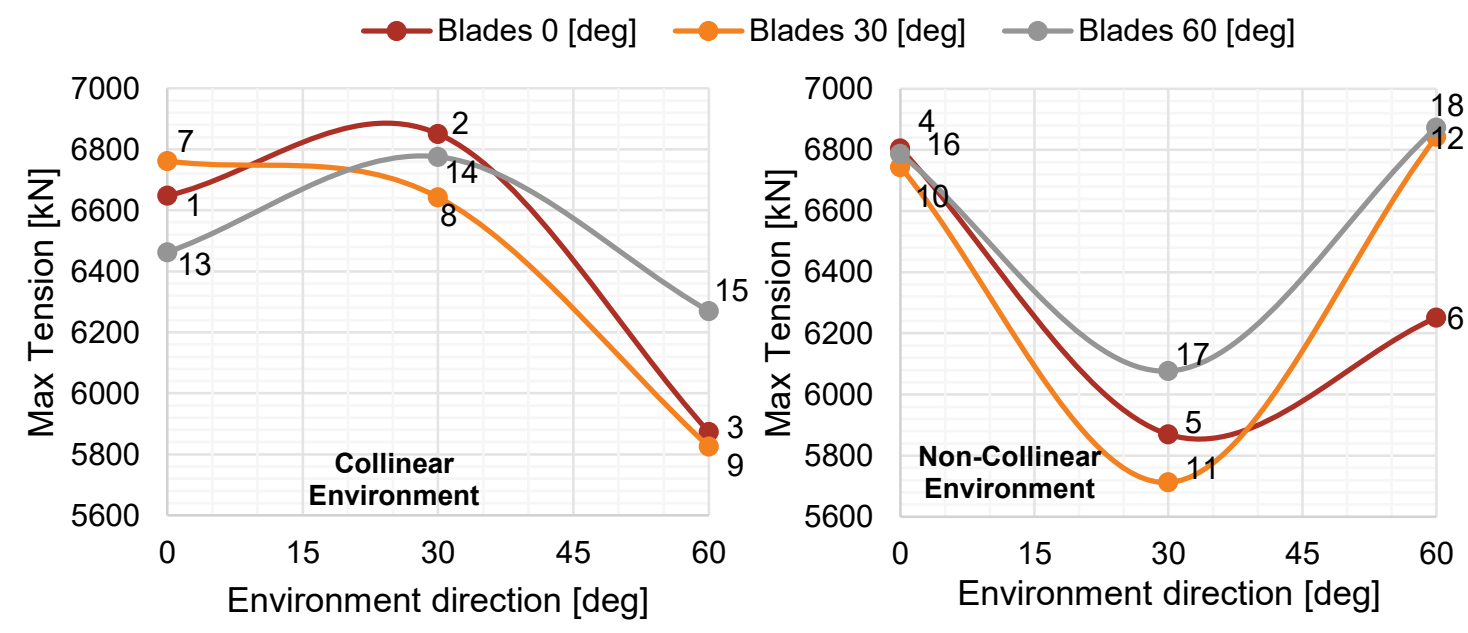

Figure 19. Maximum tension vs. environment direction per blades configuration at $0,30,60$ degrees (collinear and non-collinear environment) 


\subsection{Marine growth effects}

The mooring lines are affected by the growth of marine microorganisms; plants, algae or animals grow along the mooring lines over the years of operation. An increase in the mooring weight and a greater drag coefficient, due to the larger diameter, are consequences of this phenomenon. The worst-case scenario, in terms of mooring line tension, from the ULS analysis has been adjusted considering the corrections indicated in Table 11 and an additional simulation has been run in order to investigate the influences of the marine growth phenomenon, in accordance with DNVGL-OS-E301 [5]. The simulation results have shown that all the design requirements were achieved when the marine growth was considered in the analysis. The higher mooring weights caused a lower value of touchdown point for the mooring lines, which decreased by up to $12 \%$ compared to the case without marine growth. On the other hand, no relevant differences regarding the maximum mooring line tensions were observed. The tension values' results were slightly higher when compared with the case without marine growth, but the percentage difference between the two models remained below $1 \%$.

Table 11. Corrections for marine growth

\begin{tabular}{ccc}
\hline Mooring line & Increase in weight per unit length & Increase in $\mathbf{C}_{\mathbf{D}}$ \\
\hline Synthetic rope & $+98.02 \mathrm{~kg} / \mathrm{m}$ & +1.71 \\
Chain & $+66.98 \mathrm{~kg} / \mathrm{m}$ & +2.28 \\
\hline
\end{tabular}

\section{Conclusions}

The design and verification of the mooring system for AC Biode's FVAWT have been performed in the present study to investigate the feasibility of this floating concept. The key feature of this work has been to use an iterative framework to optimise the model by changing a range of parameters, including the ballast weight, spar size, mooring line size, mooring line layout, mooring line length and mooring line pre-tension. One of the major findings from this study is that by implementing $100 \mathrm{~m}$ of synthetic rope, about 25 tonnes of the spar structure's weight can be saved compared to the preliminary design. This is due to the lower buoyancy needed to balance the minimised weight of the mooring system. Moreover, the pre-tension of the lines has been found to have a significant impact on the dynamic behaviour of the system. The wind turbine with the optimised mooring system design achieved from this study has satisfied the ULS criteria by taking the Hywind's site into consideration. Future work needs to be performed on ALS and FLS analysis of the optimised design obtained from this study. 


\section{Acknowledgements}

The authors acknowledge Longitude Engineering and AC Biode for sponsoring this project and Cranfield University and the University of Genoa for supporting this study.

\section{REFERENCES}

[1] Orcina website, OrcaFlex software, https://www.orcina.com/

[2] "Floating Offshore Wind: Market and Technology Review", Carbon Trust, June 2015

[3] "Floating Wind Joint Industry Project", "Phase I Summary Report", Carbon Trust, May 2018

[4] "Floating axis wind turbines for offshore power generation-a conceptual study", Akimoto et al, 2011

[5] DNVGL-OS-E301, "Position mooring”, July 2018

[6] "Investigation of Hydrodynamic Forces for Floating Offshore Wind Turbines on Spar Buoys and Tension Leg Platforms with the Mooring Systems in Waves", YuHsien Lin, Shin-Hung Kao and Cheng-Hao Yang, Department of Systems and Naval Mechatronic Engineering, National Cheng Kung University, 12 February 2019

[7] "A comparison on the dynamics of a floating vertical axis wind turbine on three different floating support structures", Michael Borg and Maurizio Collu, Cranfield University, 2014

[8] "Mooring system optimization for floating wind turbines using frequency domain analysis", Matthias Brommundt, Ludwig Krause, Karl Merz, Michael Muskulus, Department of Civil and Transport Engineering, Norwegian University of Science and Technology, Trondheim, Norway, January 2012

[9] "Design and Analysis of Station keeping Systems for Floating Structures", API Recommended Practice 2SK Third Edition, October 2005

[10] "Offshore Vertical Axis Wind Turbine with Floating and Rotating Foundation", Luca Vita, PhD Report, DTU, August 2011.

[11] Hywind Project, Equinor Website: https://www.equinor.com/en/what-wedo/hywind-where-the-wind-takes-us.html

[12] Hywind Buchan Deep, Metocean Design Basis, RE2014-002

[13] Reistad, M, Breivik, Ø, Haakenstad, H, Aarnes, O J, Furuvik, B R and Bidlot, JR (2011), A high-resolution hindcast of wind and waves for the North Sea, Norwegian Sea, and the Barents Sea, Journal of Geophysical Research, 116, C05019, doi: 10.1029/2010JC006402.

[14] DNVGL-RO-C205, "Environmental Conditions and Environmental Loads", August 2017 
[15] "Spar Buoy Short Wave Issue", Orcina, https://www.orcina.com/wpcontent/uploads/Spar-Buoy-Short-Wave-Issue.pdf

[16] "Dynamic of Offshore Structures", Minoo H Patel, 1989

[17] Appendix E, DNVGL-RO-C205, "Environmental Conditions and Environmental Loads", August 2017

[18] Hywind Scotland - status and plans, EERA DeepWind' 2015, Trondheim Rune Yttervik, Statoil, https://www.sintef.no/globalassets/project/eera-deepwind 2015/presentations/closing/rune-yttervik_statoil.pdf

[19] ABS, Technical Report, "Offshore Anchor Data for Preliminary Design of Anchors of Floating Offshore Wind Turbines”, August 2013 